\title{
Perencanaan Timbunan di Belakang Pangkal Jembatan Sebagai Alternatif Pengganti Slab on Pile (Studi Kasus Jalan Lingkar Luar Barat Surabaya)
}

\author{
Anugradia Nela Putri, Noor Endah Mochtar, dan Musta'in Arif \\ Departemen Teknik Sipil, Institut Teknologi Sepuluh Nopember (ITS) \\ e-mail: noormochtar@gmail.com
}

\begin{abstract}
Abstrak-Jalan Lingkar Luar Barat (JLLB) di Kota Surabaya merupakan salah satu jalan yang telah direncanakan antara Lakarsantri dan Romokalisari, panjang $19,8 \mathrm{~km}$ dan lebar $0,51 \mathrm{~m}$, untuk mengatasi kemacetan lalu lintas yang ada. JLLB memiliki dua tipe konstruksi, jembatan (girder bridge) dan slab on pile. Konstruksi jembatan dibangun untuk melewati prasarana penting, permukiman penduduk, jalan, dan rel kereta api; tanah dasarnya lempung dengan konsistensi agak kaku. Konstruksi slab on pile dibangun diatas persawahan dimana tanah dasarnya lempung lembek. Dalam rangka mencari konstruksi yang efisien, dibuat perencanaan alternative sebagai pengganti konstruksi slab on pile. Konstruksi alternatif yang dipilih adalah konstruksi timbunan karena section JLLB tersebut tidak melewati prasarana. Hanya saja, tanah dasarnya lembek sehingga pemampatannya besar dan kemampuan mendukung beban sangat kecil. Untuk menangani masalah tersebut maka direncanakan tinggi timbunan awal setinggi 2,5-6 meter sehingga saat pemampatan berakhir maka tinggi timbunanannya sesuai dengan tinggi jalan yang direncanakan yaitu 2-4,3 meter. Untuk mempercepat selesainya pemampatan, direncanakan untuk dipasang PVD sejarak 1,2 meter dan kedalaman 12-17 meter. Juga direncanakan perkuatan timbunan dengan menggunakan mikropile yang berupa spunpile sebanyak 2-5 buah. Sementara itu, perkuatan timbunan menggunakan freyssisol dengan kekuatan tarik paraweb straps $30 \mathrm{kN}$ dan dibutuhkan 2-14 paraweb straps per lebar dinding precast freyssisol yaitu $2,23 \mathrm{~m}$.
\end{abstract}

Kata Kunci-Freyssisol, Jalan Lingkar Luar Barat Surabaya (JLLB), Mikropile, Timbunan, PVD.

\section{PENDAHULUAN}

$\mathrm{P}$ ERMASALAHAN transportasi merupakan masalah besar di Indonesia karena pertumbuhan jumlah kendaraan yang terus meningkat dari tahun ke tahun yaitu rata-rata di atas 3\%, sedangkan pembangunan infrastruktur atau pertambahan jumlah dan lebar jalan kurang dari $1 \%$ per tahunnya [1]. Surabaya sebagai kota terbesar kedua di Indonesia juga menghadapi permasalahan yang sama tentang kemacetan. Salah satu solusi yang dilakukan adalah penambahan jaringan jalan berupa jalan lingkar yang dinamakan Jalan Lingkar Dalam Timur (JLDT), Jalan Lingkar Luar Timur (JLLT), dan Jalan Lingkar Luar Barat (JLLB) seperti ditunjukkan dalam Gambar 1. Jalan Lingkar Luar Barat (JLLB) di Kota Surabaya merupakan salah satu jalan yang telah direncanakan antara Lakarsantri dan Romokalisari, panjang 19,8 km dan lebar 0,51 $\mathrm{m}$ dan memiliki dua tipe konstruksi, jembatan (girder bridge) dan slab on pile.

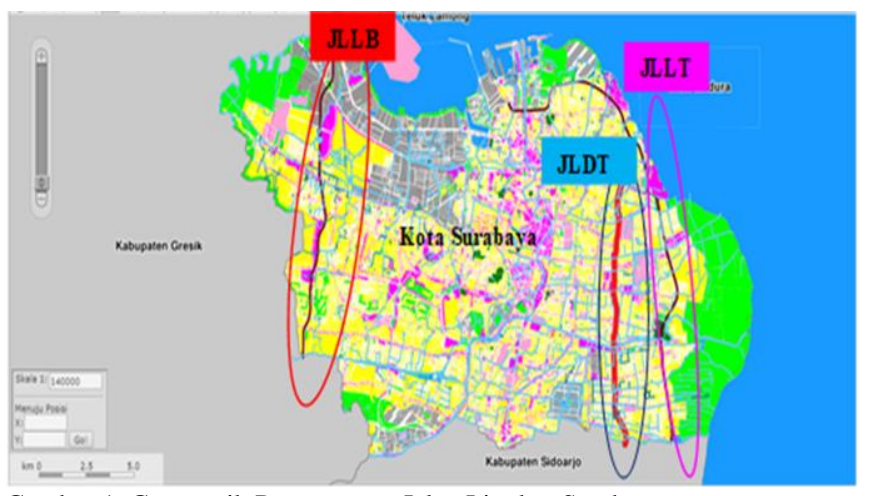

Gambar 1. Geometrik Perencanaan Jalan Lingkar Surabaya

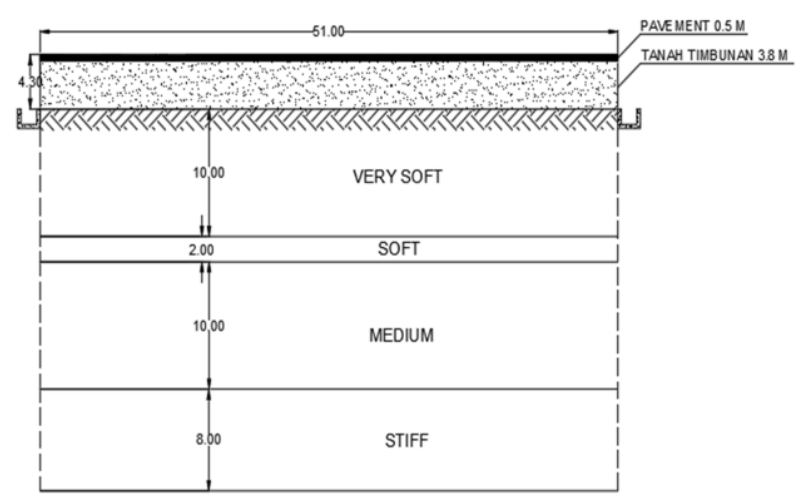

Gambar 2. Ilustrasi Perencanaan Timbunan

Konstruksi jembatan dibangun untuk melewati prasarana penting, permukiman penduduk, jalan, dan rel kereta api; tanah dasarnya lempung dengan konsistensi agak kaku. Konstruksi slab on pile dibangun diatas persawahan dimana tanah dasarnya lempung lembek. Dalam rangka mencari konstruksi yang efisien, dibuat perencanaan alternative sebagai pengganti konstruksi slab on pile. Konstruksi alternatif yang dipilih adalah konstruksi timbunan karena section JLLB tersebut tidak melewati prasarana. Hanya saja, tanah dasarnya lembek sehingga pemampatannya besar dan kemampuan mendukung beban sangat kecil. Dari kondisi tersebut akan direncanakan perbaikan tanah dengan metode surcharge dan vacuum yang dikombinasikan dengan vertical drain. Selain itu, direncanakan perkuatan timbunan sebagai dinding penahan tanah yaitu freysissol dan perkuatan apabila terjadi overall stability yaitu menggunakan mikropile. Ilustrasi perencanaan timbunan tegak dapat dilihat pada Gambar 2. 


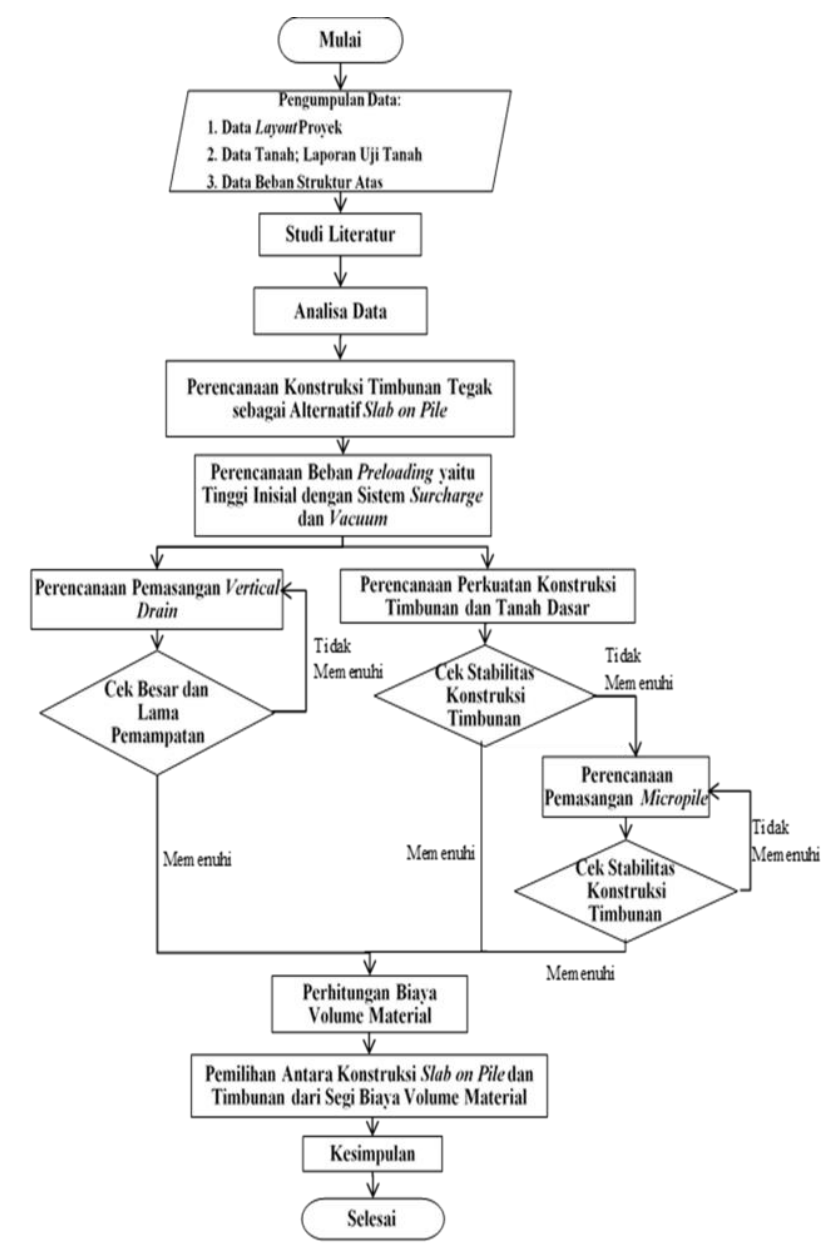

Gambar 3. Bagan Alir Perencanaan

\section{METODOLOGI}

Metodologi Perencanan ini dapat dilihat pada Gambar 3 bagan alir perencanaan.

\section{HASIL ANALISA}

\section{A. Analisa Data dan Perilaku Tanah}

Data tersebut akan digunakan untuk perencanaan timbunan pada STA 0+950 sampai STA 2+000. Tanah lunak diketahui mencapai kedalaman 22 meter pada bagian approach jembatan dan menjadi 17 meter semakin jauh dari jembatan. Data parameter tanah digabungkan dengan menggunakan distribusi statistik dengan hasil dapat dilihat pada Tabel 1.

Selain itu, dilakukan analisa terhadap perilaku tanah soft soil dan swelling soil. Pada analisa soft soil dilihat dari NSPT yang rendah [2], sedangkan swelling soil menggunakan perhitungan aktivitas swelling soil dan kurva dari Seed [3]. Dari perhitungan diketahui tanah di bawah jembatan memiliki aktivitas swelling rendah, sedangkan di bawah slab on pile memiliki aktivitas swelling medium. Oleh karena itu, pada perencanaan timbunan aktivitas swelling tidak terjadi karena tanah dasar tertutp timbunan dan pavement sehingga tidak terjadi perubahan kadar air pada tanah dasar.

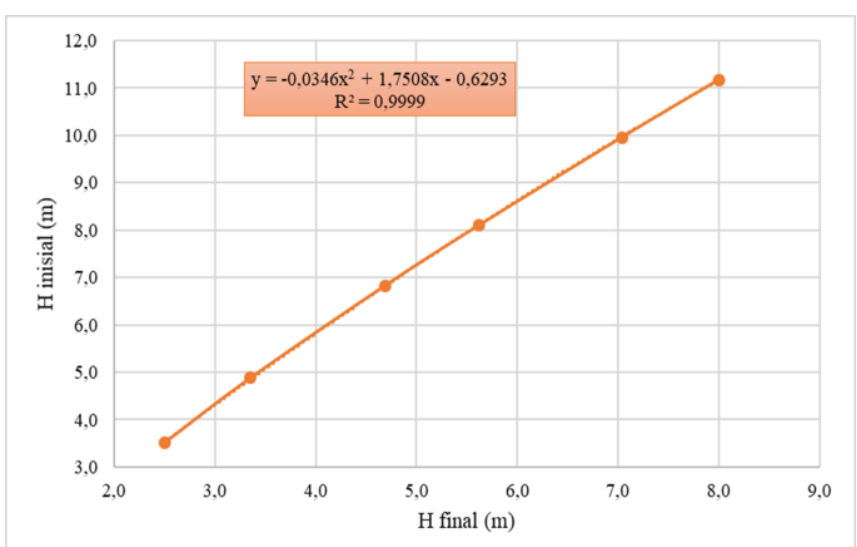

Gambar 4. Hubungan $\mathrm{H}_{\text {inisial }}$ dengan $\mathrm{H}_{\text {final }}\left(\mathrm{H}_{\mathrm{dr}}=22 \mathrm{~m}\right)$

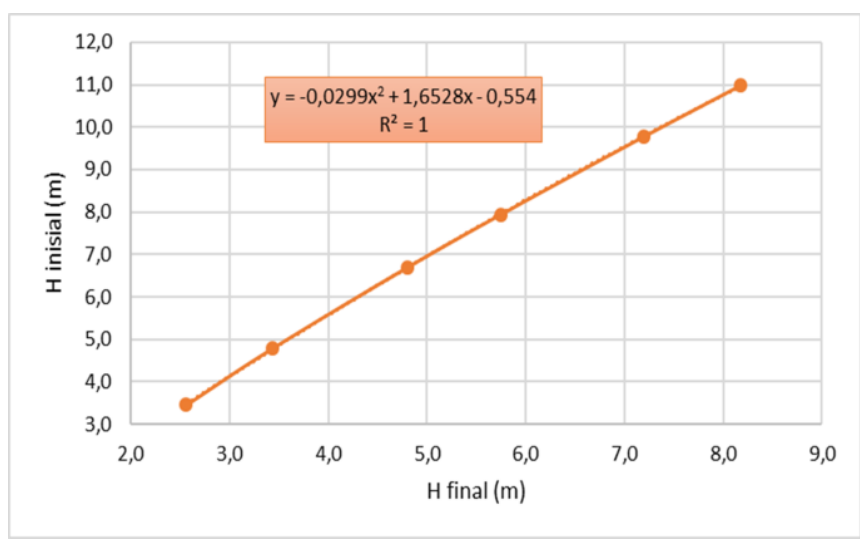

Gambar 5. Hubungan $\mathrm{H}_{\text {inisial }}$ dengan $\mathrm{H}_{\text {final }}\left(\mathrm{H}_{\mathrm{dr}}=17 \mathrm{~m}\right)$

Tabel 1.

Rekapitulasi Hasil Distribusi Statistik

\begin{tabular}{cccc}
\hline \hline \multirow{2}{*}{ Parameter } & \multicolumn{3}{c}{ Depth $(\mathrm{m})$} \\
\cline { 2 - 4 } & 5 & 10 & 15 \\
\hline ysat $\left(\mathrm{t} / \mathrm{m}^{3}\right)$ & 1,55 & 1,53 & 1,67 \\
Gs & 2,54 & 2,52 & 2,62 \\
Wc (\%) & 69,02 & 74,83 & 50,06 \\
LL (\%) & 84,17 & 89,82 & 75,07 \\
IP (\%) & 54,47 & 56,03 & 43,04 \\
$\mathrm{e}_{\mathrm{o}}$ & 1,80 & 1,93 & 1,48 \\
\hline \hline
\end{tabular}

\section{B. Perhitungan Besar dan Lama Pemampatan}

Timbunan direncanakan dengan memiliki 2 ketinggian, yaitu 4,3 m; 3,2 m; dan $2 \mathrm{~m}$. Dikarenakan tanah merupakan tanah lembek maka dilakukan perhitunan besar dan lama settlement. Besar settlement total tanah akibat adanya beban timbunan 4,3 $\mathrm{m}$ sebesar 2,0765 m; tinggi timbunan $3,5 \mathrm{~m}$ yaitu $1,736 \mathrm{~m}$; dan tinggi timbunan $2 \mathrm{~m}$ sebesar $0,8672 \mathrm{~m}$. Hasil perhitungan lama pemampatan konsolidasi didapatkan pada timbunan 4,3 $\mathrm{m}$ dan 3,5 m membutuhkan waktu 173,42 tahun; untuk timbunan dengan tinggi $2 \mathrm{~m}$ membutuhkan waktu 103,63 tahun agar derajat konsolidasi dari pemampatan mencapai 90\%. Dari hasil perhitungan besar dan lama pemampatan dapat diketahui bahwa dapat menyebabkan terjadinya differential settlement sehingga pemampatan perlu dihilangkan dan dipercepat dengan perencanaan perbaikan tanah dasar. 


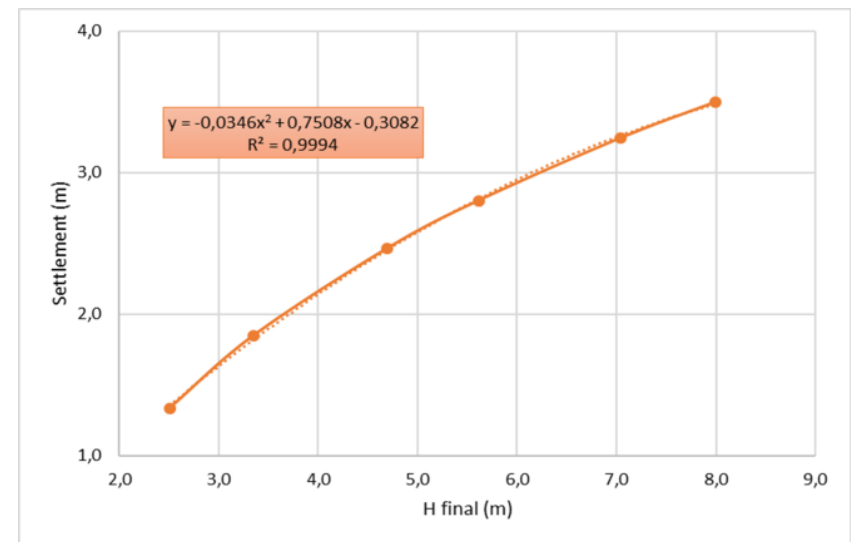

Gambar 6. Hubungan Settlement dengan $\mathrm{H}_{\text {final }}\left(\mathrm{H}_{\mathrm{dr}}=22 \mathrm{~m}\right)$

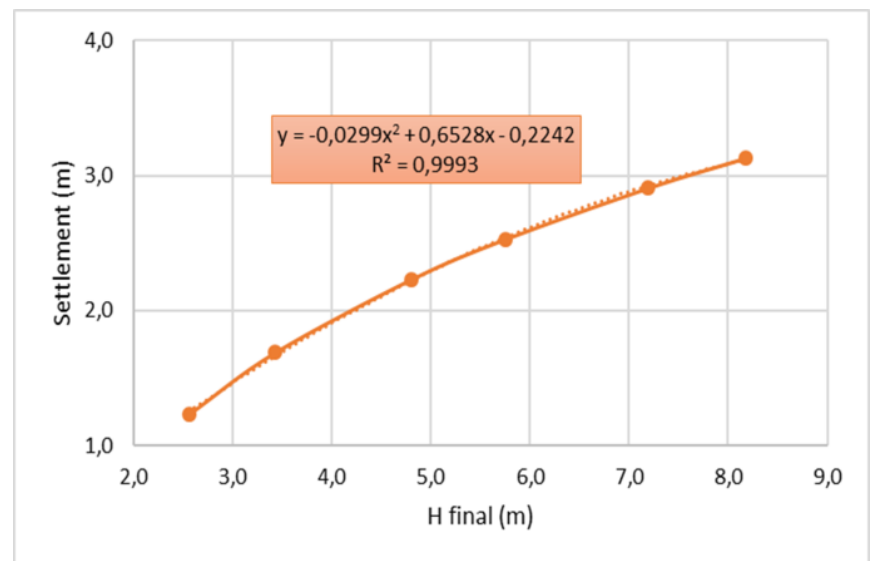

Gambar 7. Hubungan Settlement dengan $\mathrm{H}_{\text {final }}\left(\mathrm{H}_{\mathrm{dr}}=17 \mathrm{~m}\right)$

\section{Metode Perbaikan Tanah Dasar}

Ada berbagai macam teknologi dalam peningkatan daya dukung tanah lempung lunak, salah satunya adalah sistem preloading [4], [5]. Ada dua alternatif perencanaan sistem preloading yang digunakan, yaitu pemberian beban awal eksternal menggunakan metode surcharge dan beban awal internal menggunakan metode vacuum.

1) Perhitungan Tinggi Awal Timbunan

Perhitungan tersebut tidak lengsung menggunakan tinggi rencana tetapi menggunakan beberapa beban timbunan (q) yang berbeda-beda [4]. Hasil dari perhitungan adalah grafik hubungan antara $\mathrm{H}_{\text {inisial }}$ dengan $\mathrm{H}_{\text {final }}$ dapat dilihat pada Gambar 4 dan Gambar 5 dan grafik hubungan antara $\mathrm{H}_{\text {final }}$ dengan pemampatan yang dapat dilihat pada Gambar 6 dan Gambar 7 . Didapatkan tinggi awal dan settlement yang terjadi, yaitu 6,3 m; $5,1 \mathrm{~m}$; dan $2,7 \mathrm{~m}$.

\section{Percepatan Pemampatan}

Vertical drain yang digunakan merupakan Prefabricated Vertical Drain merk CeTeau-Drain CT-SD100-20 dari PT. TEKNINDO GEOSISTEM UNGGUL. Ada beberapa alternatif pemasangan PVD, yaitu menggunakan pola segitiga dan segiempat dengan jarak antar PVD 0,$8 ; 1 ; 1,2 ; 1,5 ;$ dan 1,8 meter. PVD yang direncanakan memiliki variasi kedalaman, yaitu sedalam tanah lunak, 3/4 kedalaman tanah lunak, 2/3

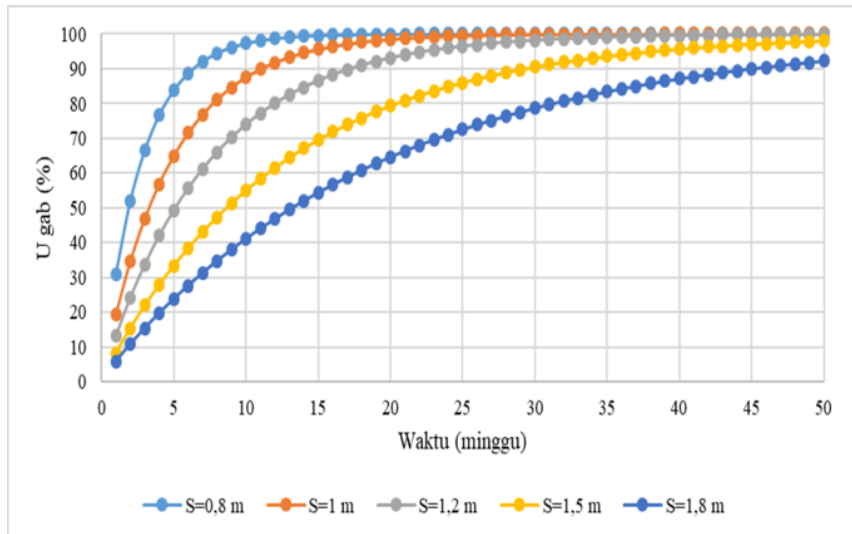

Gambar 8. Grafik Hubungan Waktu dan Derajat Konsolidasi PVD

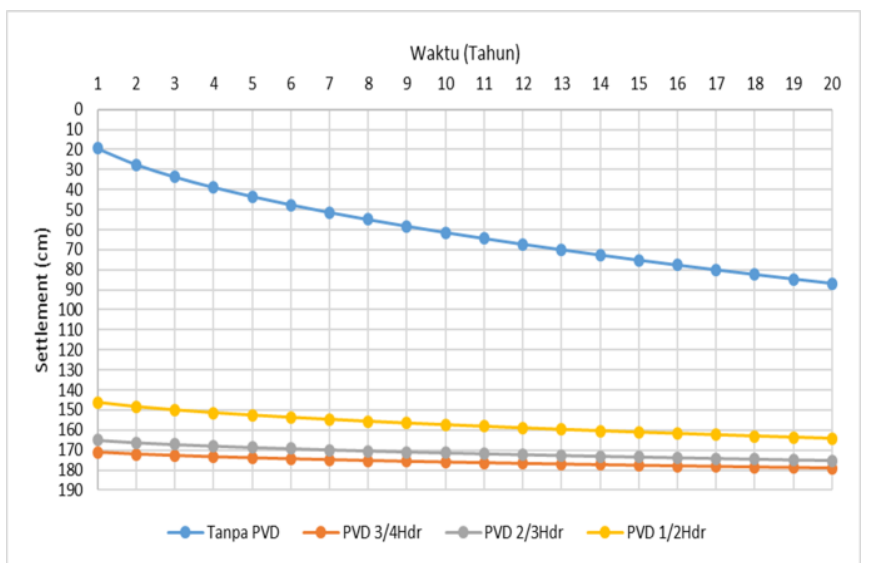

Gambar 9. Grafik Penurunan Sepanjang Tahun Rencana

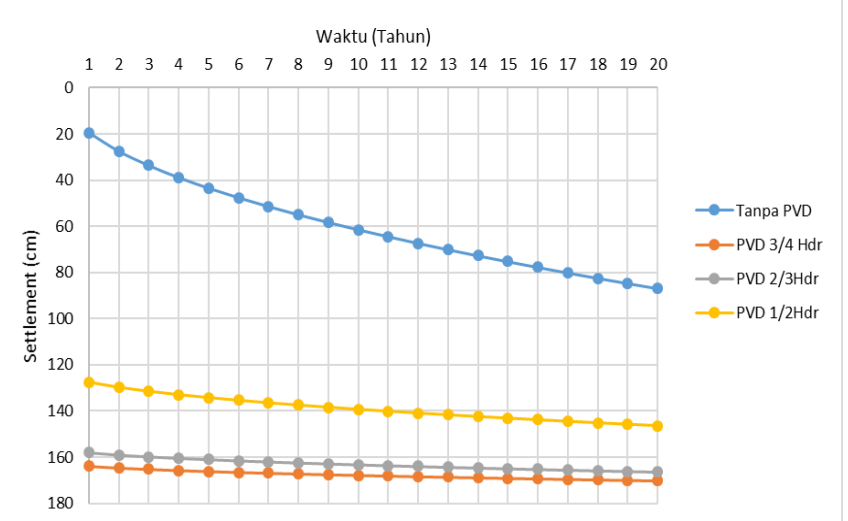

Gambar 10. Grafik Penurunan Sepanjang Tahun Rencana Jalan $\mathrm{H}_{\text {final }}=3,5 \mathrm{~m}$

kedalaman tanah lunak, dan 1/2 kedalaman tanah lunak. Hasil perencanaan PVD berupa grafik hubungan antara waktu dan derajat konsolidasi pada PVD dengan pola segiempat baik pada $\mathrm{H}_{\mathrm{dr}}=22 \mathrm{~m}$ maupun $\mathrm{H}_{\mathrm{dr}}=17 \mathrm{~m}$ dapat dilihat pada Gambar 8 .

Jarak antar PVD yang mencapai derajat konsolidasi lebih m; dan 1,2 $\mathrm{m}$. Setelah itu dilanjutkan dengan perhitungan rate of settlement untuk mencari kedalaman optimum dari PVD sehingga tidak terlalu boros dan efisien. Beberapa hasil sisa settlement masing-masing kedalaman PVD per tahun akan dijadikan grafik yang dapat dilihat pada Gambar 9, Gambar 10, dan Gambar 11. 


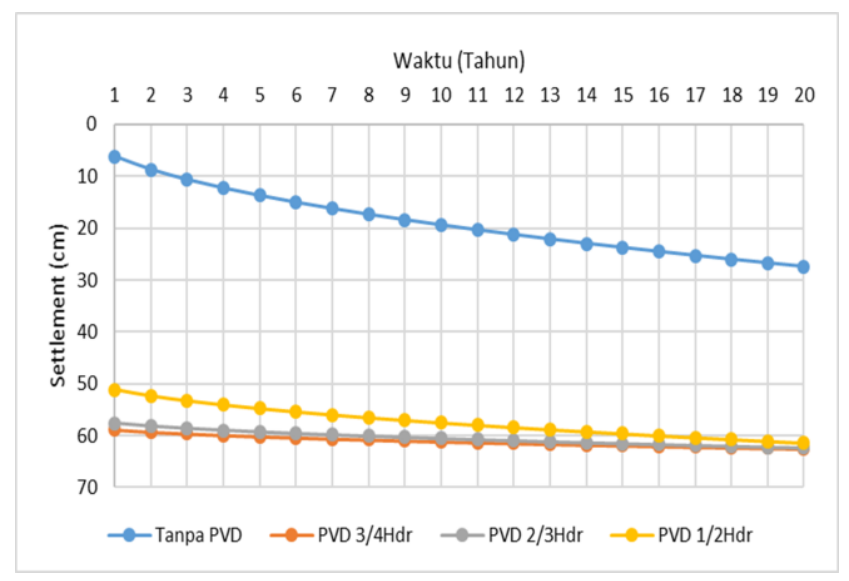

Gambar 11. Grafik Penurunan Sepanjang Tahun Rencana Jalan $H_{\text {final }}=2 \mathrm{~m}$

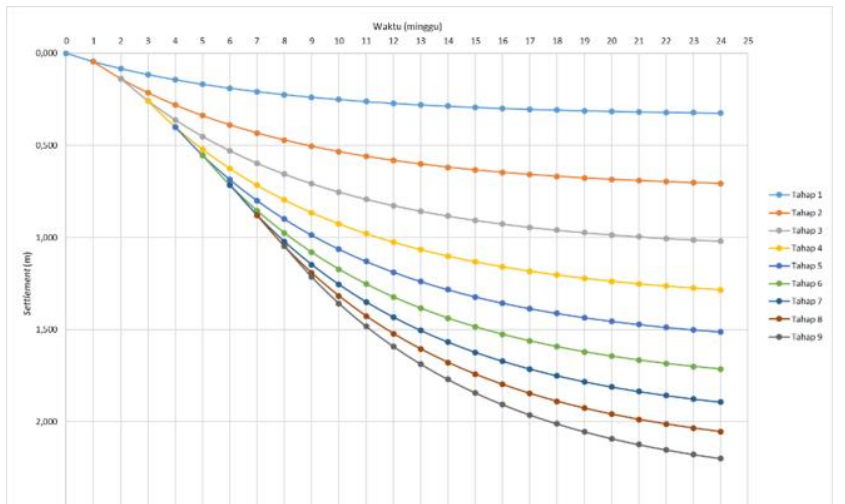

Gambar 12. Penurunan Per Minggu $H_{\text {rencana }}=4,3 \mathrm{~m}$

Tabel 2.

Kenaikan Nilai Cu Akibat Preloading dengan Surcharge $\mathrm{H}_{\text {final }}=4,3 \mathrm{~m}$

\begin{tabular}{cccc}
\hline \hline Kedalaman & PI & Cu lama & Cu baru \\
\hline $\mathrm{m}$ & $\%$ & $\mathrm{~kg} / \mathrm{cm}^{2}$ & $\mathrm{~kg} / \mathrm{cm}^{2}$ \\
$0-10$ & 54,55 & 0,046 & $0,168-0,169$ \\
$10-12$ & 56,12 & 0,094 & $0,279-0,288$ \\
$12-22$ & 43,08 & 0,343 & $0,299-0,343$ \\
\hline \hline
\end{tabular}

Tabel 3.

Kenaikan Nilai Cu Akibat Preloading dengan Surcharge $\mathrm{H}_{\text {final }}=3,5 \mathrm{~m}$

\begin{tabular}{cccc}
\hline \hline Kedalaman & PI & $\mathrm{Cu}$ lama & $\mathrm{Cu}$ baru \\
\hline $\mathrm{m}$ & $\%$ & $\mathrm{~kg} / \mathrm{cm}^{2}$ & $\mathrm{~kg} / \mathrm{cm}^{2}$ \\
$0-10$ & 54,55 & 0,046 & $0,137-0,240$ \\
$10-12$ & 56,12 & 0,094 & $0,250-0,260$ \\
$12-22$ & 43,08 & 0,343 & $0,271-0,343$ \\
\hline \hline
\end{tabular}

$$
\text { Jalan } H_{\text {final }}=4,3 \mathrm{~m}
$$

Maka diperoleh settlement per 10 tahun kurang dari $10 \mathrm{~cm}$, yaitu dengan pemasangan PVD optimum sedalam $3 / 4 \mathrm{H}_{\mathrm{dr}}$ untuk timbunan $4,3 \mathrm{~m}$ dan $2 / 3 \mathrm{H}_{\mathrm{dr}}$ untuk timbunan 3,5 dan $2 \mathrm{~m}$. Akibat pemasangan PVD tinggi awal timbunan berubah, yaitu $6 \mathrm{~m} ; 4,8$ $\mathrm{m}$; dan 2,5 m [6].

\section{E. Metode Preloading dengan Surcharge}

Salah satu sistem preloading yang digunakan adalah metode surcharge dengan memberikan beban eksternal salah satunya berupa tana h timbunan. Dalam pelaksanaan timbunan secara

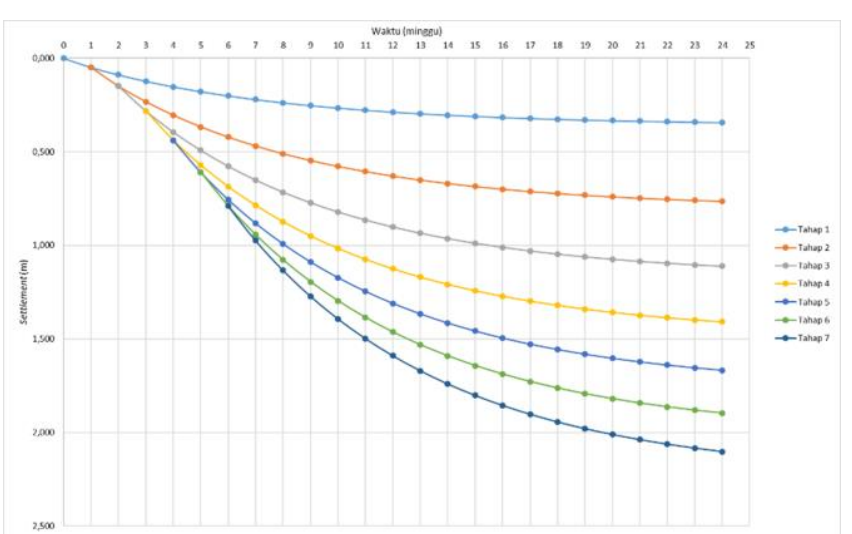

Gambar 13. Penurunan Per Minggu $\mathrm{H}_{\text {rencana }}=3,3 \mathrm{~m}$

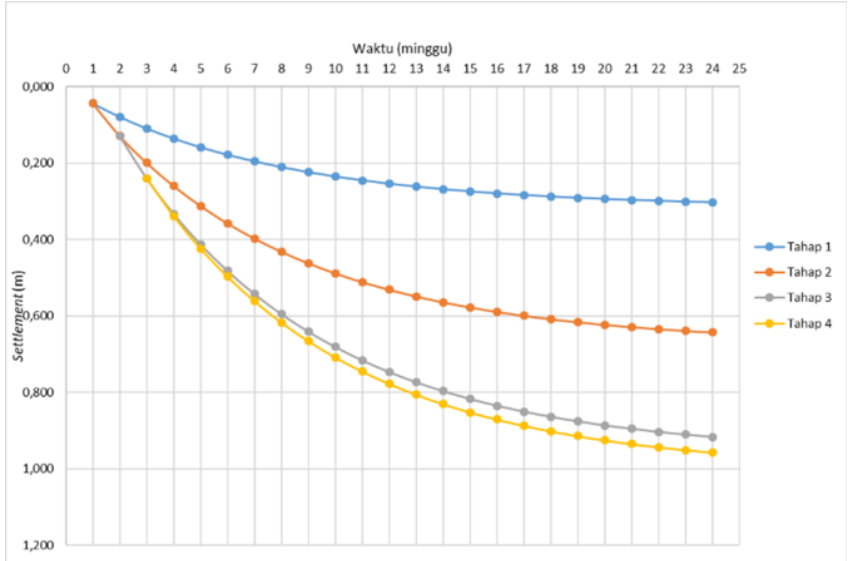

Gambar 14. Penurunan Per Minggu $\mathrm{H}_{\text {rencana }}=2 \mathrm{~m}$

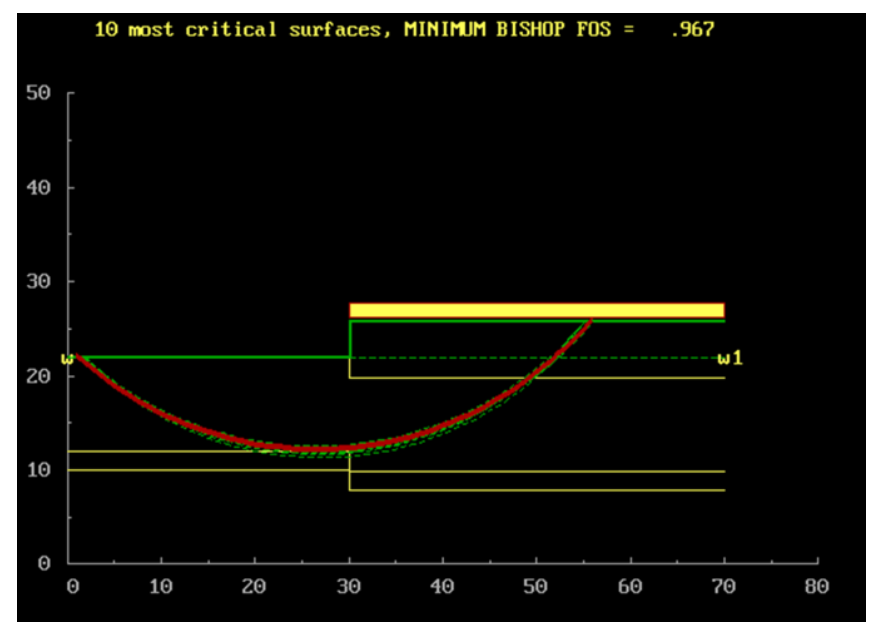

Gambar 15. Hasil Analisa Bidang Longsor dengan XSTABL

umum perlu direncanakannya timbunan bertahap [5]. Kecepatan penimbunan yang digunakan adalah $60 \mathrm{~cm}$ per minggu untuk semua tinggi rencana. Untuk menentukan pentahapan timbunan diperlukan tinggi kritis timbunan terlebih dahulu yang merupakan penentu penjadwalan pentahapan, dengan tinggi kritis 1,2 meter maka tahap 1 sampai 2 dapat dilakukan secara menerus. Timbunan yang dilaksanakan secara menerus dengan tinggi 1,2 m digunakan sebagai lantai kerja, sehingga apabila ditambahkan tahapan selanjutnya maka akan terjadi kelongdoran karena tidak ada kenaikan nilai $\mathrm{Cu}$ pada 2 minggu pertama. Perhitungan perubahan nilai $\mathrm{Cu}$ dimulai dari 
Tabel 4.

Hasil Perhitungan Kenaikan Nilai Cu (Vacuum Preloading) $\mathrm{H}_{\text {final }}=4,3 \mathrm{~m}$

\begin{tabular}{cccc}
\hline \hline Kedalaman & PI & Cu lama & $\mathrm{Cu} \mathrm{baru}$ \\
\hline $\mathrm{m}$ & $\%$ & $\mathrm{~kg} / \mathrm{cm}^{2}$ & $\mathrm{~kg} / \mathrm{cm}^{2}$ \\
$0-10$ & 54,55 & 0,046 & $0,201-0,346$ \\
$10-12$ & 56,12 & 0,094 & $0,357-0,368$ \\
$12-22$ & 43,08 & 0,343 & $0,343-0,380$ \\
\hline \hline
\end{tabular}

Tabel 5.

Hasil Perhitungan Kenaikan Nilai Cu (Vacuum Preloading) $\mathrm{H}_{\text {final }}=3,5 \mathrm{~m}$

\begin{tabular}{cccc}
\hline \hline Kedalaman & PI & $\mathrm{Cu}$ lama & $\mathrm{Cu}$ baru \\
\hline $\mathrm{m}$ & $\%$ & $\mathrm{~kg} / \mathrm{cm}^{2}$ & $\mathrm{~kg} / \mathrm{cm}^{2}$ \\
$0-10$ & 54,55 & 0,046 & $0,106-0,178$ \\
$10-12$ & 56,12 & 0,094 & $0,208-0,213$ \\
$12-22$ & 43,08 & 0,343 & $0,343-0,432$
\end{tabular}

Tabel 6.

Hasil Perhitungan Kenaikan Nilai Cu (Vacuum Preloading) $\mathrm{H}_{\text {final }}=2 \mathrm{~m}$

\begin{tabular}{cccc}
\hline \hline Kedalaman & PI & $\mathrm{Cu}$ lama & $\mathrm{Cu}$ baru \\
\hline $\mathrm{m}$ & $\%$ & $\mathrm{~kg} / \mathrm{cm}^{2}$ & $\mathrm{~kg} / \mathrm{cm}^{2}$ \\
$0-10$ & 54,55 & 0,046 & $0,111-0,244$ \\
$10-11$ & 56,12 & 0,094 & 0,256 \\
$11-17$ & 43,08 & 0,343 & $0,268-0,343$ \\
\hline \hline
\end{tabular}

Tabel 7.

Bidang Longsor XSTABL $\mathrm{H}_{\text {final }}=4,3 \mathrm{~m}$

\begin{tabular}{|c|c|c|c|c|c|c|c|}
\hline No & FOS & Xo & Yo & $\frac{\mathrm{R}}{\mathrm{m}}$ & $\mathrm{Xa}$ & $\mathrm{Xb}$ & $\begin{array}{l}\text { Mres } \\
\mathrm{kNm}\end{array}$ \\
\hline 1 & 0,968 & 29,08 & 38,51 & 23,68 & 12,11 & 49,06 & 14660 \\
\hline 2 & 0,945 & 28,06 & 39,51 & 25,08 & 10,11 & 49,06 & 15750 \\
\hline 3 & 0,919 & 26,86 & 41,71 & 28,38 & 6,44 & 50,35 & 19220 \\
\hline 4 & 0,919 & 26,82 & 44,67 & 32,56 & 3,44 & 53,35 & 24900 \\
\hline 5 & 0,968 & 26,48 & 49,19 & 36,89 & 1,56 & 55 & 30060 \\
\hline
\end{tabular}

Tabel 8.

Bidang Longsor XSTABL $\mathrm{H}_{\text {final }}=3,5 \mathrm{~m}$

\begin{tabular}{|c|c|c|c|c|c|c|c|}
\hline \multirow{2}{*}{ No } & \multirow{2}{*}{ FOS } & \multirow{2}{*}{ Xo } & \multirow{2}{*}{ Yo } & $\mathrm{R}$ & \multirow{2}{*}{$\mathrm{Xa}$} & \multirow{2}{*}{$\mathrm{Xb}$} & \multirow{2}{*}{$\begin{array}{l}\text { Mres } \\
\text { kNm }\end{array}$} \\
\hline & & & & $\mathrm{m}$ & & & \\
\hline 1 & 0,984 & 26,63 & 42,48 & 29,47 & 5,44 & 50,35 & 17570 \\
\hline 2 & 0,979 & 26,13 & 42,98 & 30,17 & 4,44 & 50,35 & 18150 \\
\hline 3 & 0,985 & 26,62 & 43,47 & 30,87 & 4,44 & 51,35 & 19210 \\
\hline 4 & 0,999 & 26,64 & 45,72 & 33,57 & 2,89 & 53,05 & 22330 \\
\hline 5 & 0,969 & 24,61 & 44,47 & 32,27 & 1,44 & 50,35 & 19950 \\
\hline
\end{tabular}

PVD sudah dipasang, yaitu pada tahap ke-2. Hasil perhitungan perubahan nilai $\mathrm{Cu}$ menggunakan perhitungan Ardana dan Mochtar [5] akibat pentahapan timbunan sisi miring dapat dilihat pada Tabel 2, Tabel 3, dan Tabel 4.

Besar penurunan per minggu sampai timbunan mencapai tinggi awal dapat dilihat pada Gambar 12, Gambar 13, dan Gambar 14.

\section{F. Metode Preloading dengan Vacuum}

Metode vacuum dilakukan dengan melakukan pemompaan vacuum dari lapisan tanah bawah lapisan tipis membran yang kedap air sehingga tegangan pori di dalam tanah dapat dibuat negatif. [5] Kerja alat $v$ acuum dipengaruhi oleh ketinggian lokasi kostruksi. Lokasi JLLB berada pada +5 DPL. Berikut adalah perhitungan beban akibat pompa vacuum:

$$
P=76-\frac{5}{100}=75,95 \mathrm{cmHg}=101,01 \mathrm{kPa}
$$

Tabel 9.

Bidang Longsor XSTABL $\mathrm{H}_{\text {final }}=2 \mathrm{~m}$

\begin{tabular}{cccccccc}
\hline \hline \multirow{2}{*}{ No } & \multirow{2}{*}{ FOS } & \multirow{2}{*}{ Xo } & \multirow{2}{*}{ Yo } & $\mathrm{R}$ & \multirow{2}{*}{ Xa } & \multirow{2}{*}{ Xb } & Mres \\
\cline { 7 - 8 } & & & & $\mathrm{m}$ & & & $\mathrm{kNm}$ \\
\hline 1 & 0,998 & 24,41 & 35,81 & 27,11 & 4,89 & 45,98 & 11430 \\
2 & 0,995 & 25,13 & 37,09 & 28,92 & 4,33 & 48 & 13240 \\
3 & 0,998 & 26,36 & 37,21 & 29,09 & 5,44 & 49,35 & 13780 \\
4 & 0,996 & 25,93 & 33,34 & 23,61 & 8,89 & 44,99 & 9049 \\
5 & 0,997 & 25,85 & 38,7 & 31,19 & 3,44 & 50,35 & 15640 \\
\hline \hline
\end{tabular}

Tabel 10.

Hasil Perhitungan Mikropile

\begin{tabular}{cccccc}
\hline \hline $\begin{array}{c}\text { H final } \\
(\mathrm{m})\end{array}$ & Jumlah & $\begin{array}{c}\text { Jarak } \\
(\mathrm{m})\end{array}$ & $\begin{array}{c}\text { Panjang } \\
(\mathrm{m})\end{array}$ & $\mathrm{Sc}(\mathrm{m})$ & $\begin{array}{c}\mathrm{H} \\
\text { inisial } \\
(\mathrm{m})\end{array}$ \\
\hline 4,3 & 5 & 1 & 13 & 0,3 & 4,1 \\
3,5 & 3 & 2 & 12 & 0,2 & 3,2 \\
2 & 2 & 2 & 10 & 0,2 & 1,7 \\
\hline \hline
\end{tabular}

Tabel 11.

Hasil Perhitungan Kebutuhan Freyssisol (Metode Surcharge)

\begin{tabular}{cccc}
\hline \hline \multirow{2}{*}{$\begin{array}{c}\text { Ketinggian } \\
(\mathrm{m})\end{array}$} & \multicolumn{3}{c}{ Pemasangan Freyssisol } \\
\cline { 2 - 4 } & H final $=4,3 \mathrm{~m}$ & H final $=3,5 \mathrm{~m}$ & H final $=2 \mathrm{~m}$ \\
\hline 1,2 & 0,4 & 0,4 & 0,5 \\
1,6 & 0,4 & 0,4 & \\
2 & 0,8 & 0,8 & \\
2,8 & 0,4 & 0,4 & \\
3,2 & 0,4 & & \\
3,6 & 0,5 & & \\
\hline \hline
\end{tabular}

Tabel 12.

Hasil Perhitungan Kebutuhan Freyssisol (Metode Vacuum)

\begin{tabular}{cccc}
\hline \hline \multirow{2}{*}{$\begin{array}{c}\text { Ketinggian } \\
(\mathrm{m})\end{array}$} & \multicolumn{3}{c}{ Pemasangan Dinding Freyssisol } \\
\cline { 2 - 4 } & H final = 4,3 m & H final = 3,5 m & H final = 2 m \\
\hline 1,2 & - & - & 0,4 \\
1,6 & - & - & 0,4 \\
1,8 & - & 0,4 & 0,6 \\
2,2 & 0,4 & 0,4 & \\
2,6 & 0,8 & 0,8 & \\
3,4 & 0,4 & 0,4 & \\
3,8 & 0,4 & 0,4 & \\
4,2 & 0,8 & 0,6 & \\
5 & 0,4 & & \\
5,4 & 0,6 & & \\
\hline \hline
\end{tabular}

Efisiensi pompa $=80 \%$

$$
\begin{aligned}
P_{\text {vacuum }} & =101,01 \times 80 \%=80,81 \mathrm{kPa} \\
& =8,08 \mathrm{t} / \mathrm{m}^{2}
\end{aligned}
$$

Perhitungan settlement setiap minggu dimulai setelah dilakukan penimbunan 1,2 $\mathrm{m}$ dan pemasangan alat vacuum sehingga pentahapan hanya dilakukan 10 tahap untuk mencapai tinggi rencana timbunan. Pada perhitungan pompa vacuum dihasilkan lama pemakaian pompa vacuum sampai mencpai settlement total.

Pada perhitungan peningkatan daya dukung ini ditinjau pada minggu vacuum dimatikan dan kedalaman tanah dasar yang mengalami kenaikan hanya sedalam PVD dipasang yaitu $3 / 4 \mathrm{H}_{\mathrm{dr}}$. Hasil peningkatan nilai $\mathrm{Cu}$ akibat vacuum dapat pada Tabel 4, Tabel 5, dan Tabel 6.

Dari hasil analisa metode perbaikan tanah dasar yang dilakukan dapat dilihat bahwa kenaikan nilai $\mathrm{Cu}$ dengan metode surcharge lebih kecil dibandingkan metode vacuum. Hal 


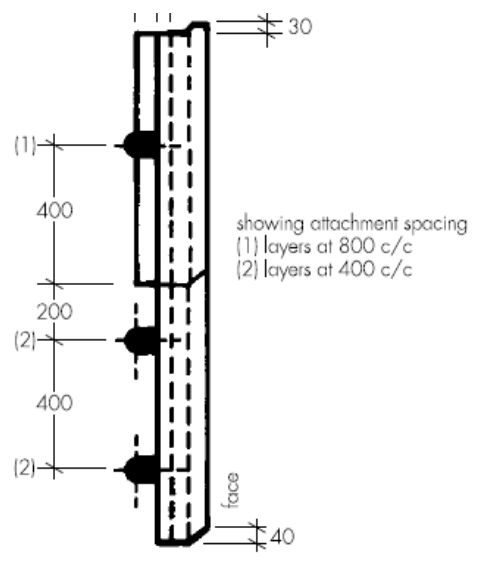

Gambar 16. Desain Beton Precast untuk Freyssisol

tersebut dikarenakan metode vacuum ada penambahan beban pompa vacuum dan pemampatan yang terjadi hilang sepenuhnya pada saat pentahapan timbunan terakhir selesai, sedangkan metode surcharge perlu 24 minggu agar derajat konsolidasi mencapai lebih dari $90 \%$ dan pemampatan selesai.

\section{G. Perencanaan Perkuatan Mikropile}

Mikropile adalah salah satu perkuatan tanah yang juga sebagai peningkatan daya dukung tanah [5]. Perkuatan mikropile menggunakan spunpile dari PT. WIKA BETON dengan diameter $30 \mathrm{~cm}$ yang memiliki data sebagai berikut:

$\begin{aligned} \text { Jenis Mikropile } & =\text { Circle Spun Pile } \\ \text { Tipe Mikropile } & =\mathrm{D}-300 \text { Kelas C } \\ \text { Produksi } & =\text { PT. Wika Beton } \\ \mathrm{D} & =300 \mathrm{~mm} \\ \mathrm{R} & =150 \mathrm{~mm} \\ \mathrm{fc} & =52 \mathrm{MPa} \\ \mathrm{t} & =60 \mathrm{~mm} \\ \mathrm{M}_{\mathrm{cr}} & =4 \text { ton.m } \\ \mathrm{M}_{\mathrm{u}} & =8 \text { ton.m }\end{aligned}$

Dalam menentukan kebutuhan mikropile perlu dilakukan analisa bidang longsor menggunakan XSTABL dengan hasil dapat dilihat pada Gambar 15. Dikarenakan iterasi dari hasil program XSTABL terbatas maka digunakan 5 bidang longsor yang memiliki initiation dan termination berbeda. Hasil analisa program XSTABL pada tinggi rencana 4,3 dapat dilihat pada Tabel 7, Tabel 8, dan Tabel 9.

Hasil perhitungan kebutuhan mikropile dapat dilihat pada Tabel 10. Perencanaan mikropile tidak diperlukan pada perencanaan timbunan dengan metode perbaikan tanah vacuum karena angka keamanan dari bidang longsor hasil XSTABL sudah lebih dari 1.

\section{H. Perencanaan Perkuatan Timbunan Freyssisol}

Freyssisol merupakan suatu konstruksi dinding penahan tanah yang juga dapat digunakan untuk perkuatan timbunan. Struktur dari freyssiol menggunakan beton-beton precast yang kemudian disusun menyesuaikan bentuk dinding atau lereng dari tanah. Keuntungan dari pemakaian freyssisol, yaitu untuk mengurangi daya tekan dari struktur atas, pemakaian perkuatan komposit sehingga anti karat, dan pelaksanaan cepat dan disesuaikan bentuk. Perhitungan gaya dorong yang diterima bergantung pada desain dari perkuatan freyssisol itu sendiri yang mana dapat dilihat pada Gambar 16. Sementara itu, gaya tarik dari paraweb straps digunakan gaya tarik ultimate 30 , sehingga gaya tarik allowable sebagai berikut:

$$
\begin{aligned}
T_{\text {allow }}= & \frac{T_{c r}}{f_{n} \cdot f_{m 11} \cdot f_{m 121} \cdot f_{m 122} \cdot f_{m 21} \cdot f_{m 22}} \\
T_{c r}= & 60 \% \times T_{\text {ult }} \\
= & 18 \mathrm{kN} \\
T_{\text {allow }} & =\frac{16}{1 \times 1 \times 1 \times 1,05 \times 1,05 \times 1,05} \\
& =15,55 \mathrm{kN}
\end{aligned}
$$

Hasil perhitungan kebutuhan freyssisol baik untuk metode perbaikan surcharge maupun vacuum dapat dilihat pada Tabel 11 dan Tabel 12.

\section{A. Perbandingan Alternatif Perencanaan Timbunan dengan} Slab on Pile

Hasil perhitungan perencanaan biaya volume material slab on pile akan dibandingkan dengan alternatif dari perencanaan timbunan baik sisi miring dan tegak. Biaya volume material slab on pile yang dibutuhkan adalah Rp 17.103.133.997, sehingga dapat disimpulkan bahwa konstruksi timbunan lebih ideal dan efisien. Alternatif perencanaan timbunan yang paling ideal dan efisien adalah timbunan sisi tegak perbaikan tanah vacuum dan perkuatan freyssisol dengan biaya volume material Rp 3.926.140.884,00.

\section{KESIMPULAN DAN SARAN}

\section{A. Kesimpulan}

Berdasarkan perencanaan yang telah dilakukan, dapat dihasilkan beberapa kesimpulan sebagai berikut:

1) Pada pangkal jembatan memiliki perilaku tanah swelling medium, tetapi karena tanah merupakan tanah lempung jenuh dengan NSPT kurang dari 10 maka tanah memiliki pemampatan besar dan lama.

2) Settlement total akibat adanya beban timbunan sisi tegak 4,3 m sebesar 2,0628 m; 3,5 m yaitu $1,726 \mathrm{~m}$; dan $2 \mathrm{~m}$ sebesar $0,8443 \mathrm{~m}$. Lama pemampatan konsolidasi didapatkan pada timbunan 4,3 $\mathrm{m}$ dan 3,5 $\mathrm{m}$ membutuhkan waktu 173,42 tahun; untuk timbunan dengan tinggi $2 \mathrm{~m}$ membutuhkan waktu 103,63 tahun.

3) Alternatif timbunan dengan perbaikan tanah vacuum dengan perkuatan freyssisol lebih ideal dan efisien dibandingkan konstruksi slab on pile.

4) Hasil perencanaan PVD yang digunakan, yaitu pola segiempat dengan jarak $1,2 \mathrm{~m}$ panjang $\mathrm{PVD} 3 / 4 \mathrm{H}_{\mathrm{dr}}$ dan PVD $2 / 3 \mathrm{H}_{\mathrm{dr}}$. Besar beban preloading yang berupa tinggi awal timbunan setelah direncanakannya PVD, yaitu $6 \mathrm{~m}$; 4,8 m; dan 2,5 m.

B. Saran

1) Kondisi di lapangan perlu diperhatikan lebih lagi dalam mempertimbangkan pemilihan perencanaan perbaikan dan perkuatan tanahnya.

2) Pada perhitungan biaya pengadaan, selanjutnya dapat diperhitungan biaya pelaksanaan.

3) Pada jembatan perencanaan lebih lanjut dapat dipertimbangkan 


\section{DAFTAR PUSTAKA}

[1] A. de Rozari and Y. H. Wibowo, "Faktor-faktor yang menyebabkan kemacetan lalu lintas di jalan utama Kota Surabaya (Studi Kasus Di Jalan Ahmad Yani Dan Raya Darmo Surabaya)," JPAP J. Penelit. Adm. Publik, vol. 1, no. 01, 2015.

[2] H. B. Seed, R. Lundgren, and others, "Prediction of swelling potential for compacted clays," J. soil Mech. Found. Div., vol. 88, no. 3, pp. 53-87,
1962.

[3] K. Terzaghi, Theoretical Soil Mechanics. New York: Wiley \& Sons, 1943.

[4] N. E. Mochtar, Modul Ajar Metode Perbaikan Tanah. Surabaya: Jurusan Teknik Sipil FTSP-ITS, 2012.

[5] I. B. Mochtar, Teknologi Perbaikan Tanah dan Alternatif Perencanaan pada Tanah Bermasalah (Problematic Soils). Surabaya, 2000.

[6] B. Marga, "Manual Desain Perkerasan Jalan Nomor 02," 2013. 